\title{
Jets costeros en Gran Canaria y Tenerife. Caracterización y mejora de la predicción
}

https://doi.org/10.31978/639-19-010-0.223

\author{
Javier Fernández Villares ${ }^{1}$ (jfernandezv@aemet.es) \\ Sergio Fernández González² (sfernandezg@aemet.es) \\ ${ }^{1}$ AEMET / Delegación Territorial en Canarias \\ ${ }^{2}$ AEMET / Dirección de Producción e Infraestructuras / Departamento de Producción
}

\begin{abstract}
RESUMEN
Cuando los flujos en niveles bajos son aproximadamente paralelos a la costa, es habitual encontrarse con máximos de viento en las cercanías de las interfases océano-tierra. Si además existe una barrera montañosa a lo largo del litoral y se dan una serie de condiciones - locales y sinópticas-, los responsables de estos máximos suelen ser estructuras mesoescalares denominadas chorros o jets costeros en niveles bajos (LLCJ, Low Level Coastal-Jet).

En Canarias, el predominio del régimen de alisio a nivel sinóptico, unido a la alta insolación y prominencia del terreno, plantea unas condiciones muy favorables a la formación de LLCJ en algunas de las vertientes de las islas de mayor relieve, con episodios intensos de viento que pueden superar los $50 \mathrm{kt}$ en cualquier época del año, pero que cobran especial relevancia durante la temporada estival. Su estudio en el archipiélago canario resulta novedoso y representa todo un reto de modelización por la pequeña escala del fenómeno y por el efecto potenciador de los pares mesoalta/mesobaja que se forman a barlovento/sotavento de las islas de mayor relieve (dipolo orográfico) y que interactúan con los propios jets. Se han empleado dos modelos no hidrostáticos de alta resolución, Harmonie-Arome a 2,5 km y un WRF con tres dominios anidados de 9, 3 y $1 \mathrm{~km}$, para caracterizar dichas estructuras y describir sus particularidades tanto en la vertiente sureste de Tenerife como en las vertientes noroeste y sureste de Gran Canaria, haciendo además hincapié en su importancia desde el punto de vista aeronáutico debido a su impacto en forma de cizalladura.
\end{abstract}

PALABRAS CLAVE: jet costero; vientos alisios; cizalladura; mesoescala; estructura baroclina; mesobaja.

\section{INTRODUCCIÓN}

Un chorro o jet costero en niveles bajos (LLCJ, del inglés Low Level Coastal-Jet) es una estructura baroclina y mesoescalar en la baja troposfera inducida por un fuerte contraste de presión entre una zona marítima y otra terrestre. Los LLCJ se encuentran confinados dentro de una capa límite atmosférica marina (MBL, Marine Boundary Layer) y se manifiestan en forma de estructuras muy estables de viento intenso y paralelo a la costa, especialmente en horas centrales y segunda mitad del día, con valores sostenidos que durante eventos intensos pueden superar los $40 \mathrm{kt}$ y rachas por encima de $50 \mathrm{kt}$. El núcleo del chorro, donde se dan estos máximos de viento, se sitúa a una altura variable, normalmente comprendida en algún punto entre los 200 m y 1000 m, dependiendo en gran medida de la altura de una inversión térmica que tapa dicha MBL.

El reflejo de estos jets costeros en superficie permitió identificar los primeros LLCJ en las inmediaciones de diversos litorales a nivel mundial, con características físicas similares pero una gama bastante amplia de 
forzamientos subyacentes (CHAO, 1985). Una de las primeras referencias fue observada por Bunker a pocos kilómetros de la costa somalí en 1965. La explicación para los vientos observados, de $12 \mathrm{~m} \mathrm{~s}^{-1}$ en superficie y de hasta $25 \mathrm{~m} \mathrm{~s}^{-1}$ en altura, apuntaba hacia una causa baroclina por el fuerte contraste térmico entre la superficie terrestre, desértica y con altos niveles de insolación diurnos, y una capa húmeda y fresca en un océano caracterizado por afloramientos de aguas frías o upwelling durante el monzón (BunKER, 1965).

Posteriormente el modelo fue sufriendo diversas depuraciones a medida que su identificación y estudio mejoraban y era ampliado a otras zonas del planeta. Desde entonces, el chorro costero mejor y más ampliamente documentado ha sido el de la costa oeste de los Estados Unidos, concretamente en los estados de Oregón (Johnson y O'Brien, 1973; Elliot y O'Brien, 1977) y California (Lester, 1985), aunque en esencia se trate del mismo fenómeno, hoy en día conocido simplemente como jet costero de California. El desarrollo del modelo físico-matemático actual, bajo el paraguas de la teoría semigeostrófica, fue definitivamente establecido a finales de los años 70 por Gill y Schumann (Gill y Schumann, 1979), que junto a otros trabajos (ZEMBA y FRIEHE, 1987; BEARDSLEY et al., 1987) permitieron establecer con precisión los elementos dinámicos cambiantes y la dependencia diurna del fenómeno, con máximos de viento en horas centrales y segunda mitad del día, y mínimos durante la noche y primeras horas de la mañana. Algunos años más tarde se estudiaría también el efecto sobre el fenómeno de accidentes geográficos con roles importantes a nivel de microescala, como los derivados de una topografía costera irregular sobre el reflejo del jet en superficie o la orientación de la orografía respecto al flujo (TJERnström y GRISOGONo, 2000; RAHN y PARISH, 2007).

El enfoque baroclino $(\rho=\rho[p, T])$ de los LLCJ resulta ineludible para explicar la distorsión barométrica mesoescalar a la que, en última instancia, deben su existencia estas estructuras, y que posee dos componentes bien definidas: una orográfica y otra dinámica. Este es el motivo por el cual los LLCJ no pueden ser descritos en términos puramente barotrópicos y por el que se hace necesario introducir un tratamiento baroclino, el semigeostrófico, que tenga en cuenta las fluctuaciones térmicas del terreno debidas a la insolación. El epígrafe 2 repasará la interrelación entra ambas condiciones, mientras que el epígrafe 3 indagará en cómo y por qué el entorno sinóptico en Canarias restringe fuertemente la ubicación de los LLCJ de Tenerife y Gran Canaria como consecuencia de la orientación de la costa respecto al gradiente barométrico sinóptico dominante.

Frente a los mecanismos bien establecidos de formación y mantenimiento de LLCJ en escalas tradicionales del orden de centenares de kilómetros (con grandes cordilleras paralelas a la costa, como en las vertientes pacíficas de Sudamérica y Norteamérica), este paper pretende poner el foco en los dos elementos novedosos respecto a la bibliografía clásica de los jet costeros. En primer lugar, la pequeña escala del fenómeno, con todos los matices que eso acarrea tanto en el marco teórico como en la modelización del fenómeno. En segundo lugar, la determinante influencia del par mesoalta/mesobaja inducido orográficamente por las islas, y cuya interacción con el propio chorro costero obliga a reformular el modelo original: la presencia de sendas mesobajas a sotavento (al suroeste, SW) de Gran Canaria y de Tenerife actúa como un forzamiento adicional fundamental con gran impacto en los regímenes de viento en los flancos a sotavento de las islas.

\section{FUNDAMENTOS FÍSICOS DE LOS JETS COSTEROS EN CANARIAS. CARACTERÍSTICAS MESOESCALARES}

Los cuatro ingredientes fundamentales que definen el establecimiento de un LLCJ mesoescalar son: 1) una MBL húmeda y estable como consecuencia del upwelling; 2) la presencia de una inversión térmica persistente, que actúa de tapadera dinámica de dicha MBL; 3) la existencia de una barrera orográfica cercana a la costa, sometida además a variaciones térmicas diurnas drásticas fruto de una alta insolación; y 4) la ubicación y orientación de una serie de reguladores locales, tanto de origen dinámico como orográfico, que regulan la intensidad y dirección del reflejo en superficie del jet costero. Particularizando estas condiciones en el entorno canario:

1. El upwelling, propiciado por la cercanía de la costa occidental africana y el régimen predominante del nordeste (alisios), favorece la existencia de una MBL húmeda, estable y particularmente fría (dada la 
latitud) durante la mayor parte del año. La variación térmica de la temperatura superficial del mar en Canarias es pequeña durante el año, generalmente algo menor y más fría en las islas orientales $\left(17-23^{\circ} \mathrm{C}\right)$, y mayor y más cálida en las occidentales $\left(19-25^{\circ} \mathrm{C}\right)$.

2. El clima canario se encuentra fuertemente influenciado por la presencia al noroeste (en promedio) del anticiclón semipermanente de Azores. Su efecto subsidente actúa como tapadera de la capa límite planetaria e inhibe la actividad convectiva durante la mayor parte del año. Su ubicación relativa respecto al archipiélago propicia la aparición de una inversión térmica persistente superior al $95 \%$ del tiempo en los meses de verano, e incluso alrededor del $80 \%$ en los meses de invierno (véase fig. 1). La altura media de la inversión es más baja durante los meses de verano, comprimiendo el flujo en la vertical y causando su aceleración, pudiendo situarse la misma por debajo de los $500 \mathrm{~m}$ de altura.
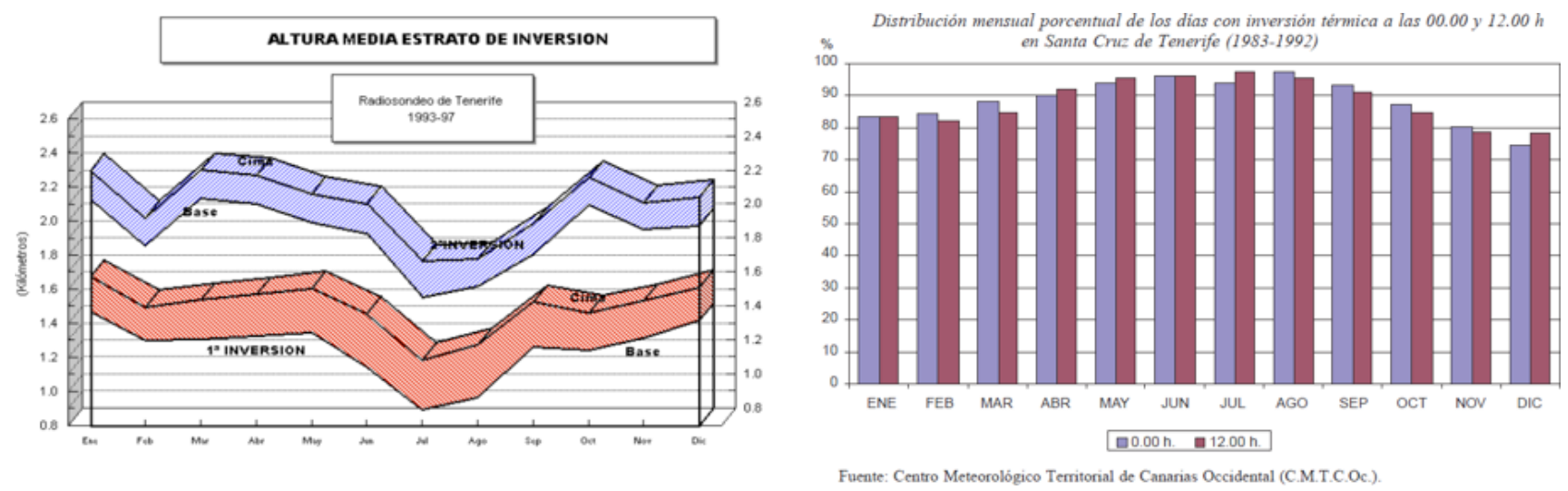

Figura 1. Altura media de inversión (la relevante es la 1. ${ }^{\mathrm{a}}$, la más cercana a la superficie) y distribución porcentual mensual a partir del radiosondeo en Santa Cruz de Tenerife. AEMET.

3. La presencia de una barrera orográfica cercana a la costa, unida al calentamiento diurno del terreno en las vertientes sureste (SE) y noroeste (NW) de Gran Canaria y SE de Tenerife, introducen una distorsión barométrica mesoescalar en la interfase océano-tierra, cuyo efecto provoca un hundimiento de la inversión en las cercanías de la interfase tierra-océano (imagen izquierda en la fig. 2), lo que a su vez repercute en el gradiente de presión horizontal efectivo en niveles bajos cerca de superficie. Este debilitamiento desigual de la estabilidad entre tierra (por el hundimiento de la inversión térmica) y sobre la zona marítima propicia la aparición de un jet costero con núcleo en la base de la inversión tal y como predice la teoría semigeostrófica (imagen derecha en la fig. 2, que resume y enumera los tres puntos anteriores).
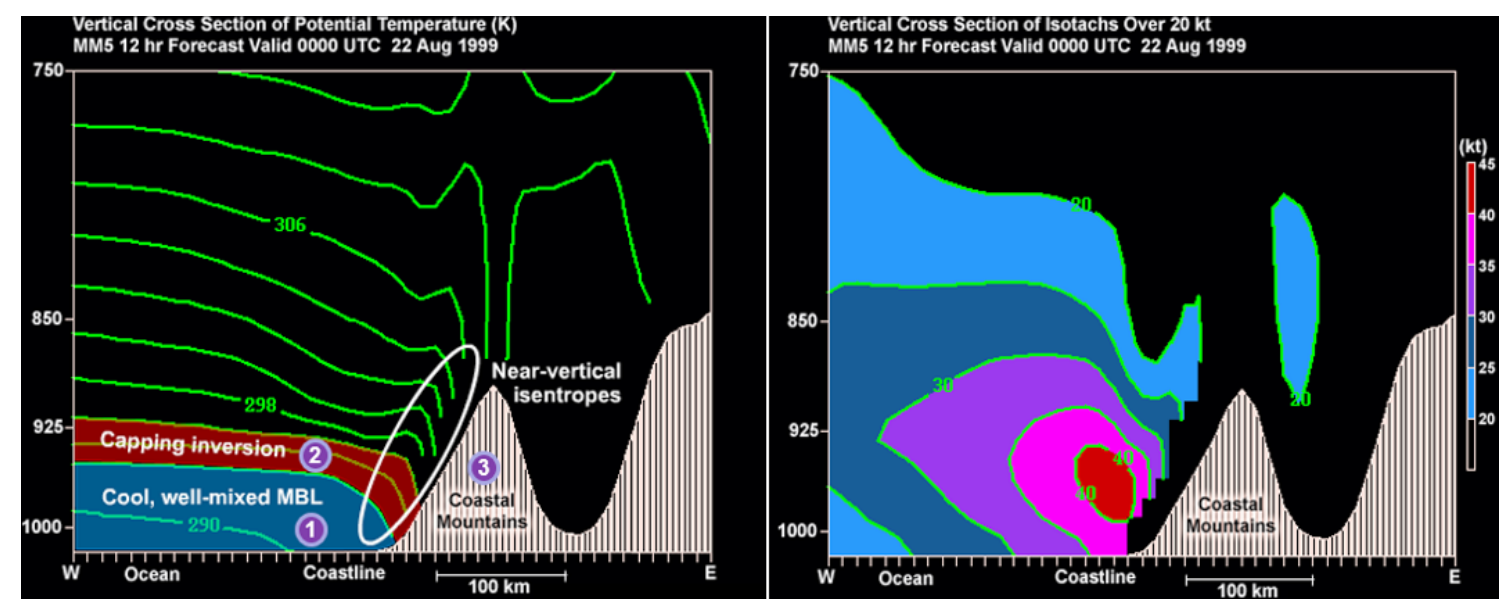

Figura 2. Corte vertical de temperatura potencial y debilitamiento de la estabilidad sobre la interfase agua-tierra por anomalía isentrópica (izquierda) e isotacas del jet (derecha). Fuente: COMET. 
4. Por último, dos tipos de reguladores locales, dinámicos y orográficos, modifican y regulan la intensidad del viento cerca de la superficie (reflejo del jet en superficie). Sus efectos son sutiles y complementarios, además de altamente dependientes de elementos microescalares, por lo que se analizan en detalle en los siguientes párrafos.

Reguladores dinámicos. Dada la curvatura de las isentropas en la interfase océano-tierra en la imagen izquierda de la fig. 2 y, por tanto, de la aparición de un gradiente barométrico horizontal efectivo, parece razonable esperar la aparición de un flujo ageostrófico de mar a tierra similar a una brisa tal y como sugiere la imagen izquierda de la fig. 3 .

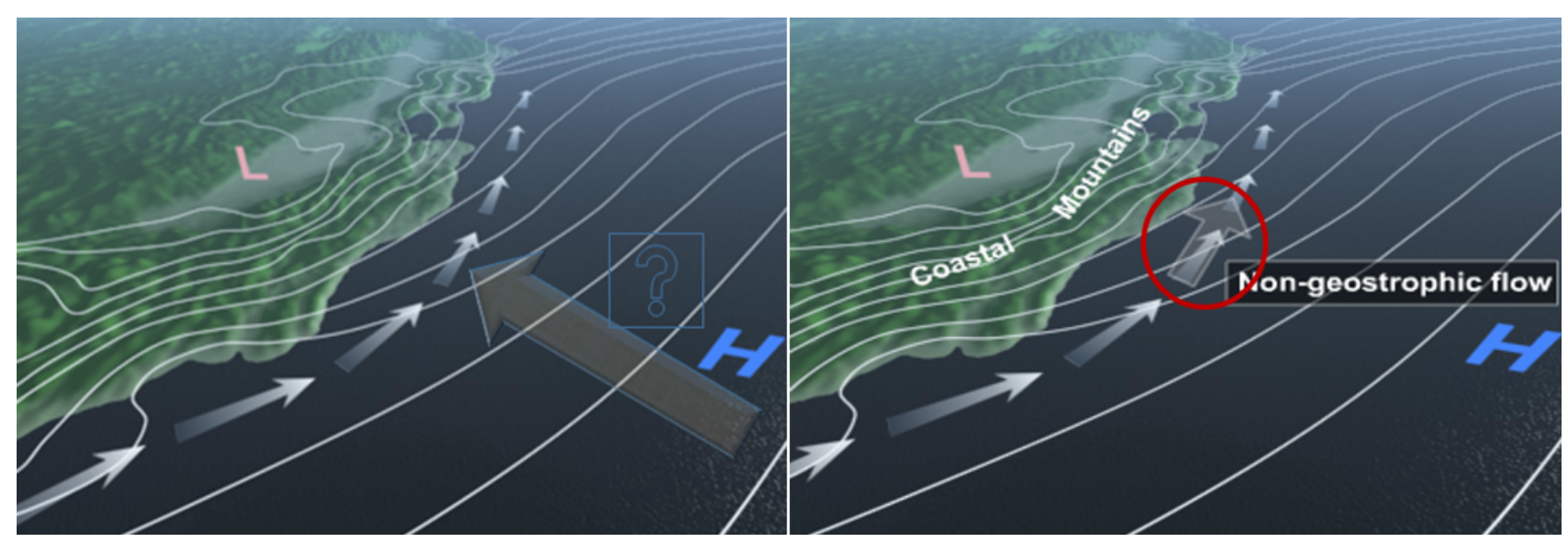

Figura 3. A la izquierda, el flujo ageostrófico en forma de brisa que, conceptualmente, cabría esperar.

A la derecha, lo que ocurre realmente por el efecto combinado del bloqueo orográfico y

la presencia de una inversión térmica que actúa como tapadera del flujo. Fuente: COMET.

Sin embargo, la dupla orografía más inversión térmica (con la base de dicha inversión por debajo del tope del obstáculo orográfico, claro está) se traduce en un bloqueo de ese potencial flujo ageostrófico, que termina sumándose a la componente aproximadamente geostrófica del propio chorro (fig. 3 derecha). Esto es lo que ocurre en Gran Canaria y Tenerife, con inversiones que cuando se encuentran por debajo de las cimas de las islas (bajo los $1500 \mathrm{~m}$, aproximadamente) permiten la formación de dichas estructuras. Cuando la inversión térmica se encuentra a mayor altura, la orografía ya no es capaz de contener el flujo, el hundimiento de la inversión es mucho menos pronunciado, los vientos no son apenas acelerados y las estructuras en forma de chorro costero resultan difícilmente discernibles.

En la práctica, el efecto de las brisas no solo potencia la intensidad del flujo, sino que también causa una leve variación de la dirección observada del viento, especialmente durante la segunda mitad del día cuando el diferencial térmico tierra-océano es máximo. Estas variaciones entre el día y la noche están bien estudiadas en el aeropuerto de Gran Canaria y suelen traducirse en un giro de la dirección del viento de entre $20^{\circ}$ y $40^{\circ}$. La extrapolación de este rango de valores a otros lugares de la isla no resulta posible debido a la alta dependencia con la orografía de dicho fenómeno a nivel de microescala.

Reguladores orográficos. Por otro lado, el reflejo del jet en superficie no es constante, sino que experimenta máximos a sotavento de cabos y promontorios a lo largo de la costa, y mínimos a barlovento de los mismos. Tales efectos no pueden ser explicados por mecanismos dinámicos. ¿Qué los motiva?

El flujo paralelo a la costa se agolpa en la vertical a barlovento de cabos y promontorios (Hydraulic jump en fig. 4), y se expande lateralmente y acelera a sotavento (Expansion fan, reduciendo su altura pero abarcando una mayor extensión mar adentro), en una suerte de «efecto Venturi costero» (imagen derecha en la fig. 4). La analogía en este caso hace referencia a que, mientras que un Venturi clásico es puramente orográfico, aquí se da una mezcla de elementos dinámicos (gradiente de presión en dirección océano-tierra más inversión térmica) y geográficos (superficie del mar y barrera montañosa) que, en conjunto, actúan como un encauzador del flujo. 

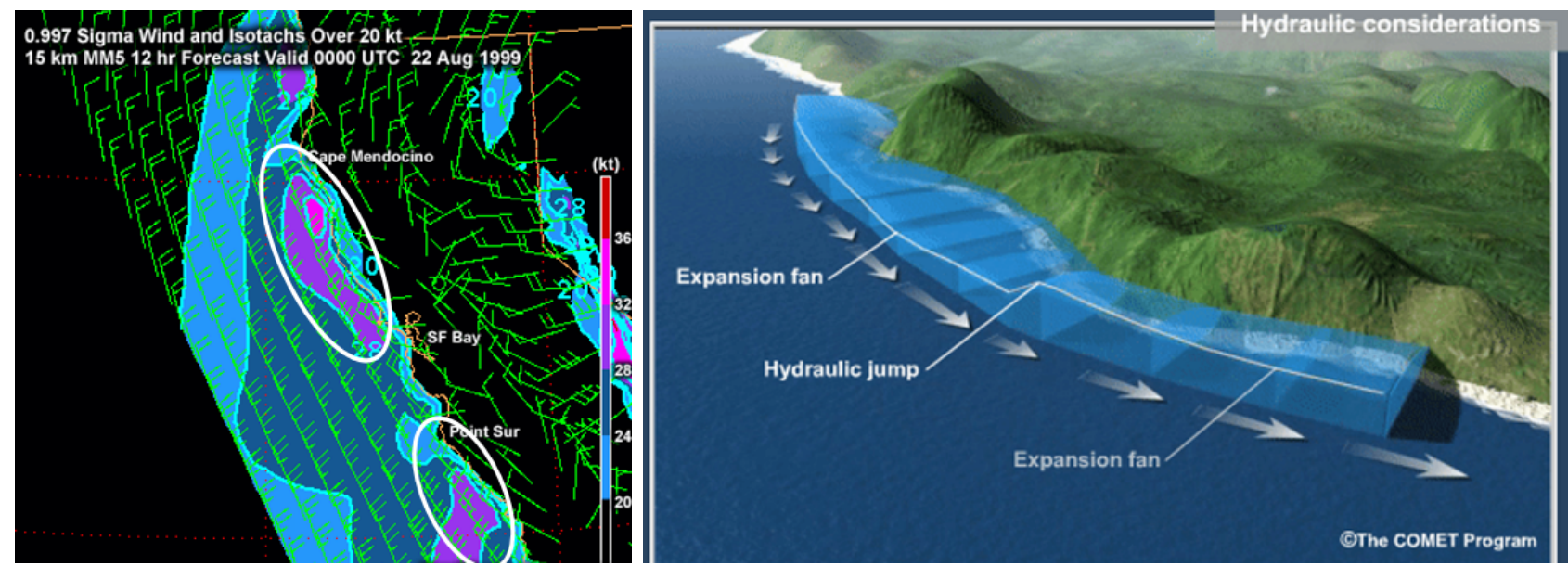

Figura 4. Máximos de viento a sotavento de cabos en la costa de California (izquierda) y modelo conceptual de la teoría hidráulica (derecha). Fuente: COMET.

El efecto combinado, predicho por la teoría semigeostrófica y denominado teoría hidráulica, resulta especialmente eficiente en Gran Canaria, con aceleraciones del flujo a sotavento de las montañas de Gando y de Arinaga en Gran Canaria (más sobre esto en el epígrafe 3.3).

\subsection{Particularidades de los jets costeros en Canarias: mesoaltas, mesobajas y cola del jet}

Una diferencia importante frente al modelo clásico de jet costero se observa en los flancos a sotavento de las islas de mayor relieve mostrados en la fig. 5 (y no únicamente en Gran Canaria y Tenerife). En las salidas del modelo se aprecia la persistencia de los chorros varias decenas de kilómetros a sotavento de las islas, como si la distorsión barométrica introducida por la orografía y las características del terreno se mantuviese en los flancos «viento abajo» de las islas. En situaciones de verano, con viento intenso e inversiones térmicas muy bajas (por debajo de los $600 \mathrm{~m}$ ), estas «colas» del jet pueden superar los $100 \mathrm{~km}$ de longitud.

La explicación a este hecho se encuentra en el fenómeno de dipolo orográfico, esto es, la existencia de pequeñas mesoaltas (mesobajas) a barlovento (sotavento) de las islas de mayor relieve, y cuya presencia mantiene una anomalía de presión entre cada una de las dos vertientes de las islas de mayor relieve, provocando que los respectivos jets persistan varios kilómetros «viento abajo». El modelo conceptual de este mecanismo está bien establecido: cuando el viento se encuentra con un obstáculo tiende a bordearlo o sobrevolarlo, según la estabilidad atmosférica.

En el contexto bajo estudio, con una inversión térmica bien establecida y con tope por debajo de los $1500 \mathrm{~m}$, ocurre lo primero, dando lugar a una acumulación de flujo a barlovento (mesoalta) y de déficit a sotavento (mesobaja); en tal escenario, el flujo se acelera en los bordes del obstáculo. Este diferencial mesobaja/mesoalta se hace tanto más intenso cuanto más fuerte es el alisio y, por tanto, la cola del jet resulta más alargada cuanto

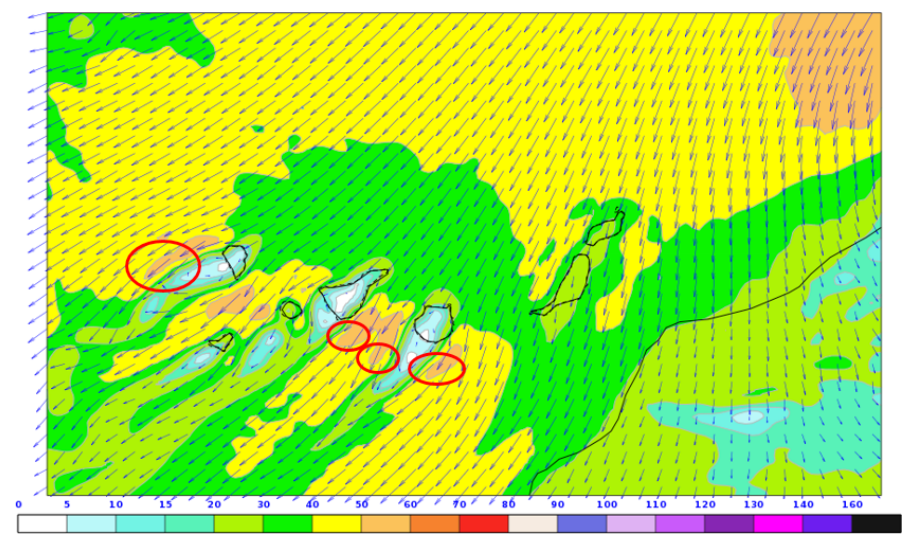
más intensa es la componente sinóptica del viento. Este caso es muy habitual durante la época estival, con inversiones que incluso pueden situarse por debajo de los $500 \mathrm{~m}$ y colas de jets superiores al centenar de kilómetros.

Figura 5.

Viento medio en superficie en $\mathrm{km} / \mathrm{h}$ durante un evento con LLCJ el 13/05/2018. 


\section{MARCO METEOROLÓGICO CANARIO E INFLUENCIAS SINÓPTICAS: GRAN CANARIA Y TENERIFE}

La existencia de la anomalía barométrica mesoescalar entre océano y tierra descrita en el epígrafe anterior es, en última instancia, la causante de los establecimientos de LLCJ en Canarias. Se han descrito también las dos componentes de dicha anomalía (orográfica y dinámica), y por qué es necesario el efecto combinado de ambas para permitir la formación y establecimiento del jet. Cuando una de las condiciones no se cumple, como ocurre por ejemplo en la vertiente norte de Tenerife (debido a un terreno con una amplia cubierta vegetal, y por tanto poco propicio a experimentar grandes contrastes térmicos diarios), rara vez se observan estructuras homologables a LLCJ a pesar de existir a priori una predisposición desde el punto de vista sinóptico.

El primer apartado de este epígrafe cubre precisamente esa predisposición e influencia de las condiciones sinópticas en la formación de LLCJ en Canarias.

\subsection{Entorno sinóptico y jet costero de características estivales}

El entorno sinóptico del archipiélago canario ha sido objeto de amplio estudio. En verano, la alta consistencia de una baja térmica sobre el Sáhara y de un anticiclón semipermanente en las inmediaciones de las islas Azores produce una situación isobárica en forma de dipolo sobre las islas, con una situación de fuerte gradiente barométrico absolutamente dominante en niveles bajos y circulación casi ininterrumpida de alisios (NE), operativa prácticamente el $90 \%$ del periodo. En invierno la situación se torna mucho más variable, pero aun así el régimen de alisios tiene una incidencia aproximada del $50 \%$. En términos anuales, se puede hablar de una frecuencia del alisio del 70-75\% anual, o de casi tres de cada cuatro días del año.

La configuración sinóptica más habitual para la formación de jets costeros se muestra en la fig. 6 (arriba a la izquierda) con el ejemplo del jet californiano. Consiste en un par formado por una alta presión semipermanente sobre el océano más una baja presión térmica sobre tierra, donde se ha señalado la dirección del gradiente efectivo de presión sinóptico $\left(\mathbf{P}_{\mathrm{S}}\right)$. En la zona de intersección (barométrica) de ambos sistemas es donde tienen lugar los LLCJ, en un entorno marítimo (MBL) caracterizado por el upwelling y un fuerte contraste térmico tierra-océano.

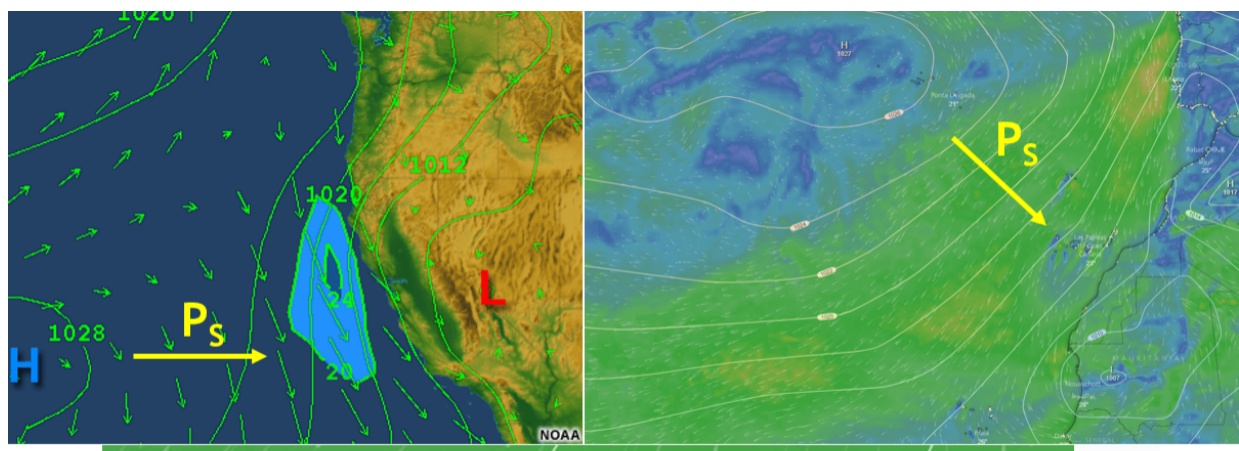

Condiciones sinópticas en

California vs. Canarias;

y zum con la dirección del

viento y los gradientes de

presión sinóptico $\left(\mathbf{P}_{\mathrm{S}}\right)$

y local $\left(\mathbf{P}_{\mathbf{L}}\right)$, más un corte

vertical esquemático de

la situación mesoescalar.

Fuentes: COMET y Windy.

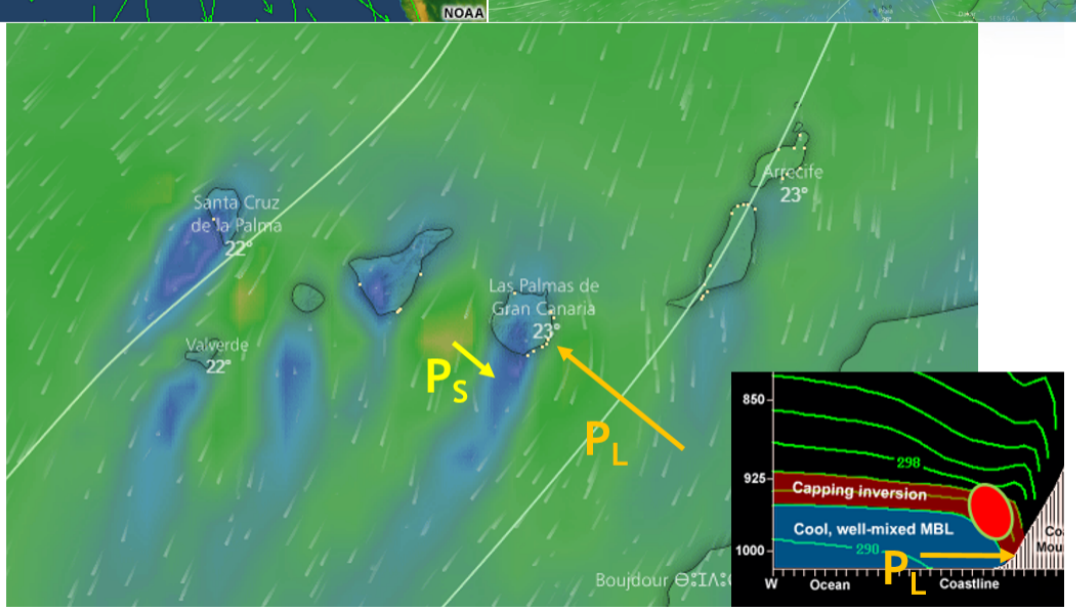


La imagen superior derecha en la fig. 6 presenta el caso típico estival en Canarias, y la parte de abajo muestra un versión ampliada de dicha situación y un corte vertical esquemático.

Una diferencia importante entre la ocurrencia del fenómeno en California y Canarias se da en las vertientes SE de ambas islas (no así en el NW de Gran Canaria), donde la dirección del gradiente sinóptico dominante ( $\mathbf{P}_{\mathrm{S}}$ en las imágenes), aunque débil, es opuesta a la que permite el establecimiento del LLCJ. La hipótesis de trabajo planteada en este paper para explicar esta aparente contradicción es la clara dominancia del gradiente de presión local $\left(\mathbf{P}_{\mathbf{L}}\right)$ entre la masa de aire marítima $(\mathrm{MBL})$, densa y fría, y el mencionado hundimiento de la inversión térmica en la interfase océano-tierra propiciado por el debilitamiento de la estabilidad, tal y como plantea Parish (PARISH, 2000). Esto ocurre tanto en las costas SE y NW de Gran Canaria, donde el terreno es muy seco y por tanto susceptible de calentamiento debido a la insolación, mientras que en Tenerife ocurre únicamente en la costa SE (la costa NW goza de mucha vegetación). Esta explicación, sustentada tanto por las observaciones como por los campos de modelos no hidrostáticos que se muestran en el epígrafe 4, aporta robustez a la hipótesis, y explica la ausencia de jets costeros en la costa NW de Tenerife. El hecho de que los valores observados de viento en el NW de Gran Canaria, donde $\mathbf{P}_{\mathrm{L}}$ y $\mathbf{P}_{\mathrm{S}}$ sí se encuentran alineados, no sean sustancialmente superiores a los de la costa SE también apoya la preponderancia de $\mathbf{P}_{\mathbf{L}}$ frente a $\mathbf{P}_{\mathrm{S}}$ (la componente sinóptica del gradiente de presión es muy débil frente a la local).

Por último, recalcar que la configuración aquí denominada estival puede darse en cualquier estación del año. Es durante el verano, no obstante, cuando efectivamente alcanza su apogeo tanto en intensidad como en frecuencia.

\subsection{Localizando los LLCJ de Gran Canaria y Tenerife. Zonas más expuestas}

La fig. 7 muestra las zonas de formación de LLCJ en Gran Canaria y Tenerife. En el caso de la vertiente NW de esta última, como se ha explicado en la introducción de este epígrafe, la condición baroclina (calentamiento de la superficie terrestre) no se cumple, evitando la formación de un chorro costero. En Gran Canaria se da en ambas vertientes, como ilustra la imagen inferior de la figura.

Una diferencia importante entre ambas islas viene impuesta por el relieve. Mientras que la costa SE de Tenerife es aproximadamente longitudinal y además coincide con la dirección del viento (prácticamente cualquier viento sinóptico en el rango $0-90^{\circ}$ es encauzado orográficamente en el canal Anaga-Agaete por la prominencia de las dos islas capitalinas), Gran Canaria posee una forma circular, y esto se traduce en un jet costero mucho más «flexible» en la vertiente SE de la isla, la de mayor importancia poblacional y por impacto

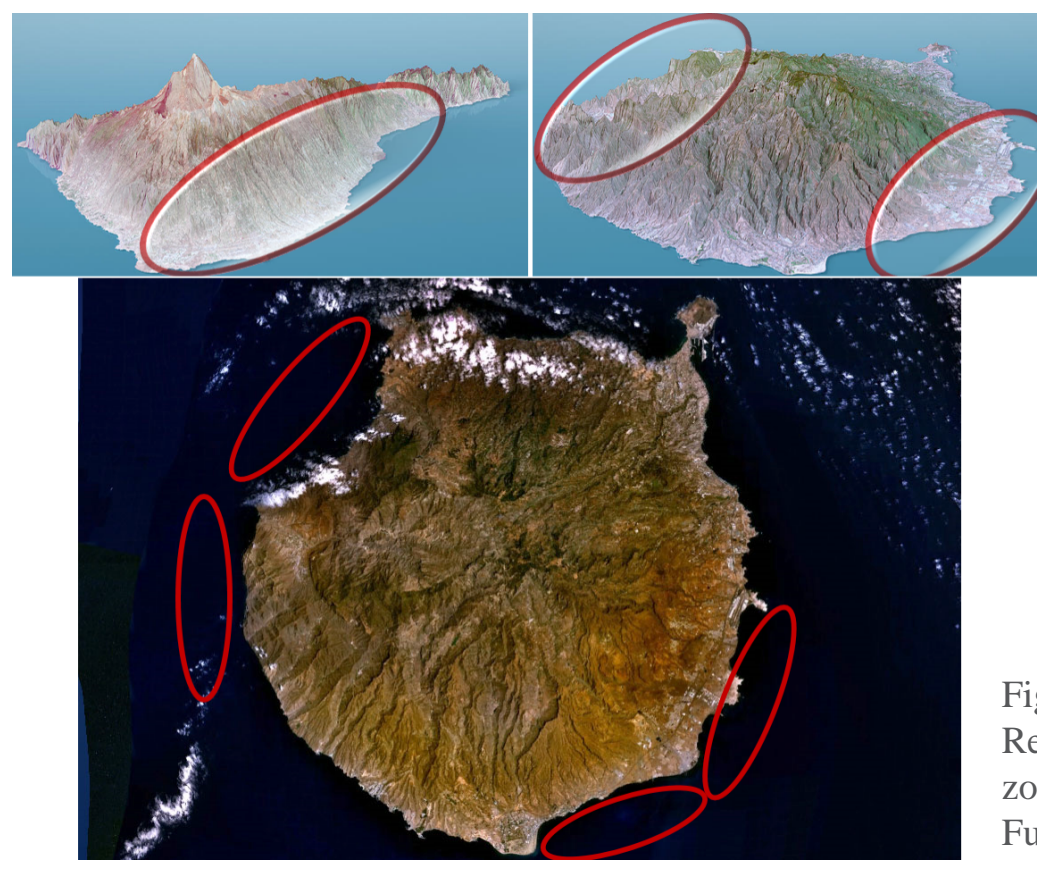
aeronáutico. La mencionada flexibilidad o adaptabilidad del jet al entorno geográfico lo es en el sentido de que su posición se mueve a lo largo de la costa según la componente sinóptica del viento proceda del NW/N o NE/E. Este fenómeno, por su interés práctico, se estudia en profundidad en el siguiente epígrafe.

Figura 7.

Relieves de Gran Canaria y Tenerife y zonas de incidencia de LLCJ.

Fuente: NASA. 


\subsection{Variabilidad del jet costero en Gran Canaria. Reguladores locales}

En el epígrafe 2 se describía la existencia de reguladores locales orográficos del reflejo del jet en superficie, de mayor importancia a efectos prácticos que el comportamiento del núcleo del propio jet en altura, en general mucho más estable.

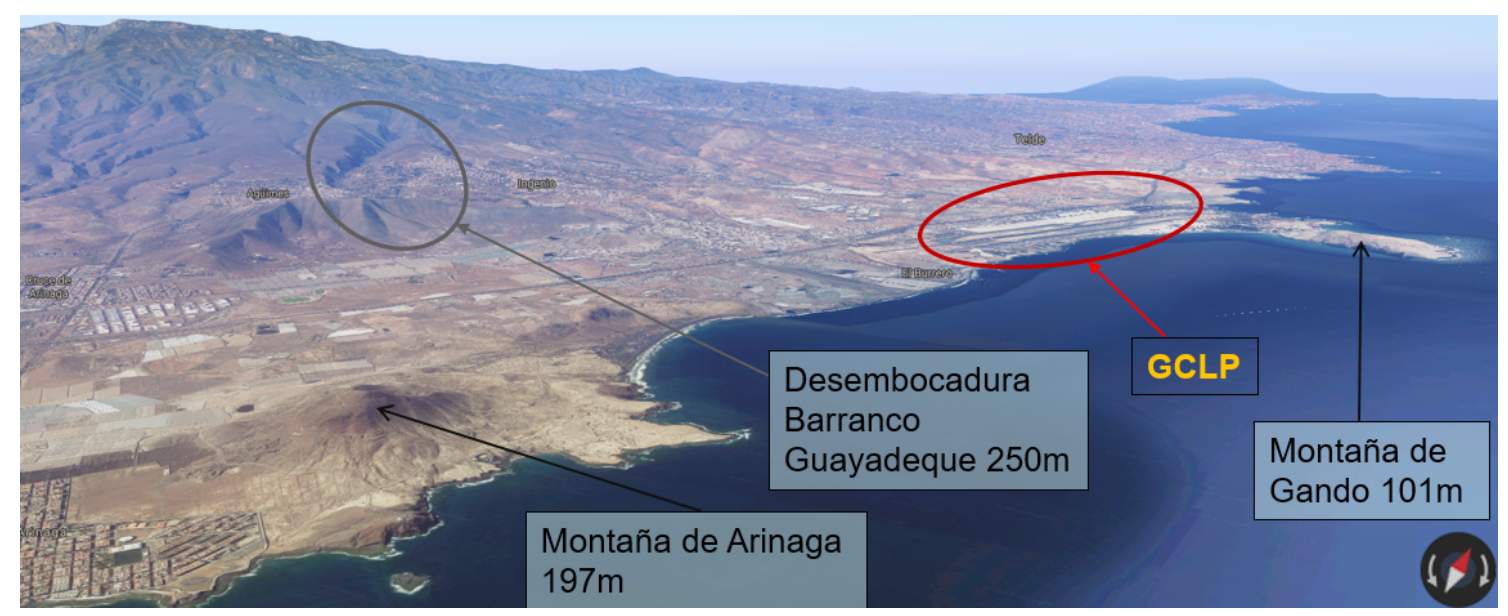

Figura 8. Reguladores locales del jet en superficie en Gran Canaria y zonas de máxima aceleración del reflejo del jet en superficie en Gran Canaria con N/NE. Fuente: Google Maps.

Los elementos orográficos más destacados que afectan al LLCJ de la costa SE de Gran Canaria vienen señalados en la fig. 8, junto con la ubicación del aeropuerto de Gran Canaria (GCLP). En situación de alisio y con dirección del viento en el rango $0-45^{\circ}$, la máxima aceleración del flujo se da a sotavento de los reguladores locales del flujo, las montañas de Gando y Arinaga, en las zonas señaladas en la fig. 8. Y más concretamente, se dan vientos más intensos en las cercanías de Pozo Izquierdo, a sotavento de la montaña de Arinaga, que en las inmediaciones del aeropuerto o bahía de Vargas, a sotavento de la montaña de Gando, por la mayor prominencia del primer obstáculo frente al segundo y que intensifica el efecto de compresión y aceleración del flujo predicho por la teoría hidráulica en el epígrafe 2 (Expansion fan).

Cabe destacar que los efectos de estos reguladores locales ocurren a escala menor de la que los modelos empleados, a la resolución actual, son capaces de captar, por lo que sería necesario algún tipo de parametrización adicional para poder contemplarlos.

En el caso menos habitual de un alisio muy tumbado del este (con dirección del viento comprendida entre los 45-90 ${ }^{\circ}$, e incluso algo más con dirección ligeramente del ESE), típico de los meses de octubre a diciembre, no existen reguladores orográficos análogos a las montañas de Gando y Arinaga que aceleren el flujo de manera significativa. Este es también uno de los motivos por los que las aceleraciones en superficie en la zona sur no son nunca tan intensas — ni tan frecuentes_ — como a sotavento de las montañas de Gando y Arinaga en la vertiente este de la isla.

\section{MODELOS Y VALIDACIÓN}

El principal modelo testado para detectar jets costeros de niveles bajos en el entorno de Canarias ha sido HARMONIE-AROME. Se empleó inicialmente tanto en su versión 38h1.2 (H38), el modelo de mesoescala no hidrostático operativo en AEMET hasta junio de 2017, como el ciclo 40h1.1 (H40), la versión más reciente del mismo y actualmente establecida de manera operativa (a fecha de enero de 2019). Ambas versiones de este modelo de área limitada se caracterizan por su formulación no hidrostática y representación no espectral (SEITY et al., 2011), con un grid horizontal de 2,5 km en toda la geografía canaria y 65 niveles 
verticales hasta el tope de $10 \mathrm{hPa}$. Tanto la orografía como los dominios de ambos ciclos del modelo son idénticos y se presentan en la imagen izquierda de la fig. 9. Una descripción detallada de estos modelos puede consultarse en BENGTSSON et al. (2017).

Aunque de prestaciones muy similares, se ha comprobado que el funcionamiento del último ciclo (H40) tiende a ajustarse más al viento real en el rango de vientos de interés (tanto en viento medio como en rachas máximas) durante regímenes de alisio (es decir, con direcciones de viento en el rango $0^{\circ}[\mathrm{N}]$ y $90^{\circ}[\mathrm{E}]$ ) y en las zonas costeras de interés (costa SE de Tenerife y costas NW y SE de Gran Canaria).

De manera adicional, y especialmente para observar el efecto e interacción del jet con las mesobajas existentes a sotavento de Gran Canaria y Tenerife, se han llevado a cabo varias simulaciones con el modelo Weather Research and Forecasting (WRF). WRF es un modelo tridimensional no hidrostático, descrito por SKAMAROCK y KLEMP (2008). Las simulaciones se han llevado a cabo usando las condiciones iniciales del NCEP-GFS con una resolución de $0,25^{\circ} \times 0,25^{\circ}$ (unos $20 \mathrm{~km}$ para la latitud de las islas Canarias), y con una resolución temporal de 3 horas (SAHA et al., 2010). Adicionalmente, se han definido 3 dominios anidados con resoluciones de 9, 3 y $1 \mathrm{~km}$ respectivamente, con $100 \times 100$ puntos de malla cada uno. Se han definido 60 niveles sigma, con resolución creciente en superficie ( 8 niveles verticales en los primeros $120 \mathrm{~m}$ sobre el nivel del suelo, y 20 en los primeros $1000 \mathrm{~m}$ ). En cuanto a las parametrizaciones físicas, se ha empleado el esquema de microfísica Thompson de seis clases (Thompson et al., 2008), los nuevos esquemas de radiación de onda corta y larga de Goddard (CHOU et al., 2001) y el esquema de PBL de MellorYamada-Janjic (JANJIC, 1990).
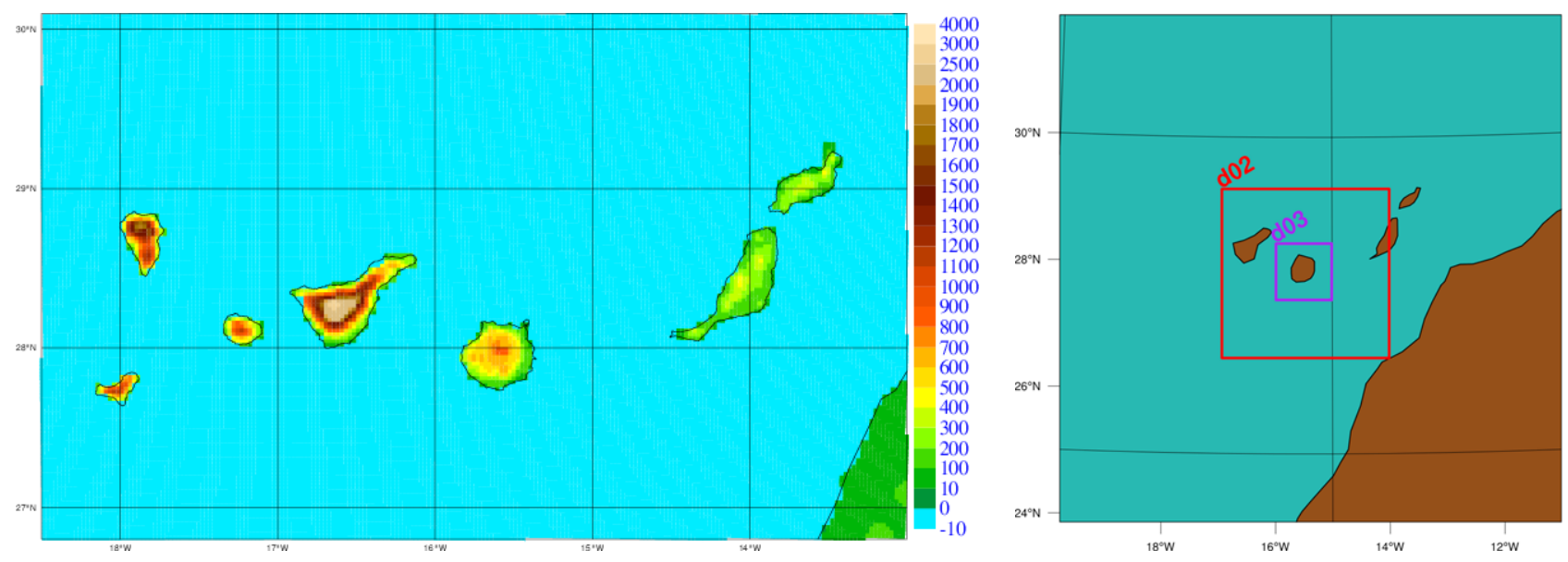

Figura 9. A la izquierda la orografía de HARMONIE-AROME.

A la derecha, los tres dominios anidados de WRF con resoluciones de 9, 3 y $1 \mathrm{~km}$ respectivamente, y $100 \times 100$ puntos de malla cada uno. Fuente: AEMET.

\subsection{Casos de estudio de LLCJ en Gran Canaria y Tenerife}

Durante la semana del 10 al 16 de mayo se experimentó un alisio continuado que permitió la formación de LLCJ en las zonas de interés de ambas islas de manera casi ininterrumpida. Dos de los días, el sábado 12 y el domingo 13, el viento fue de especial intensidad y AEMET emitió sendos avisos amarillos por viento intenso en las costas SE de las dos islas.

La fig. 10 muestra los campos de vientos medio a $10 \mathrm{~m}$ arrojados por Harmonie-Arome 40h1.1 (H40 de ahora en adelante) el día 10 de mayo a las 14Z, tanto a nivel de todo el archipiélago como en la propia isla de Gran Canaria. En la imagen derecha se observa el flujo sinóptico del viento, en el rango de los 10-15 kt, y a la izquierda la formación de sendos LLCJ tanto en las vertientes W como SE de la isla (obsérvense los 

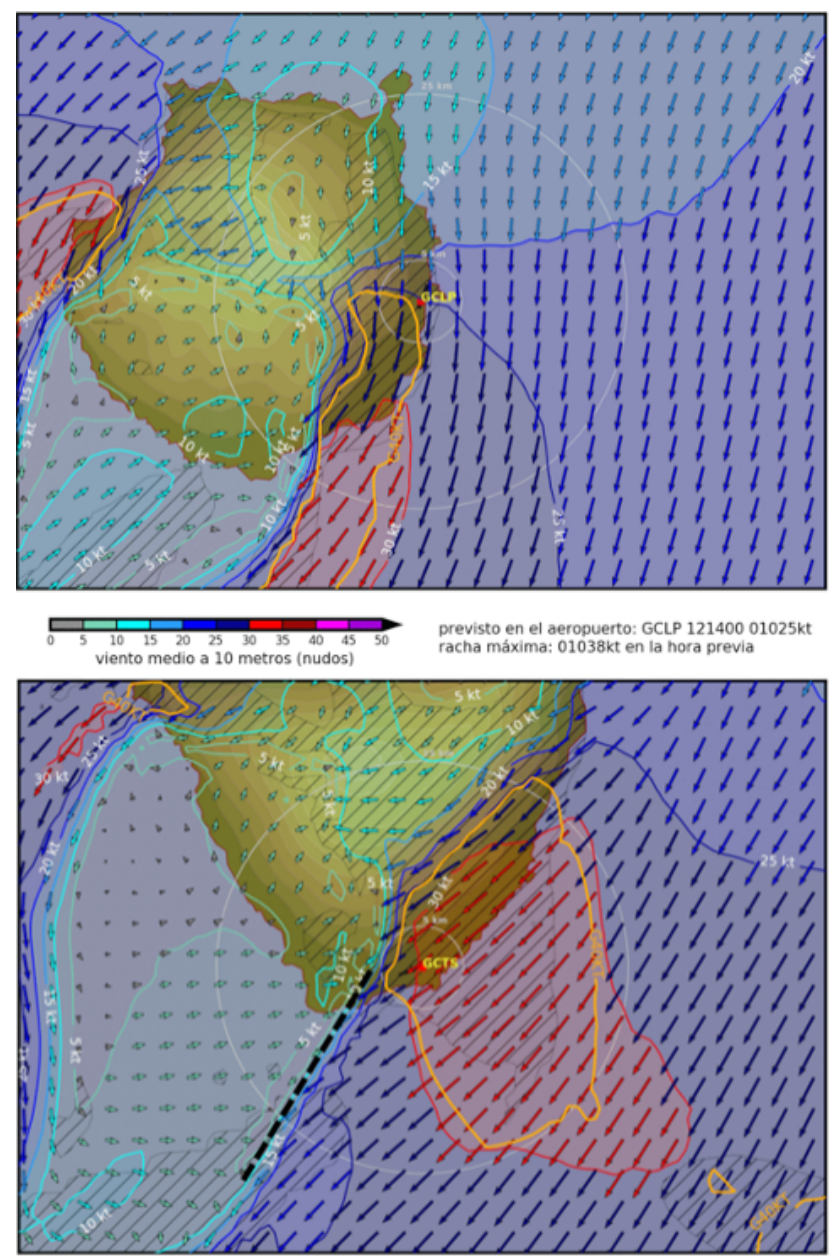

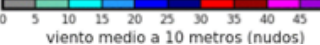

previsto en el aeropuerto: GCTS $12140005030 \mathrm{kt}$
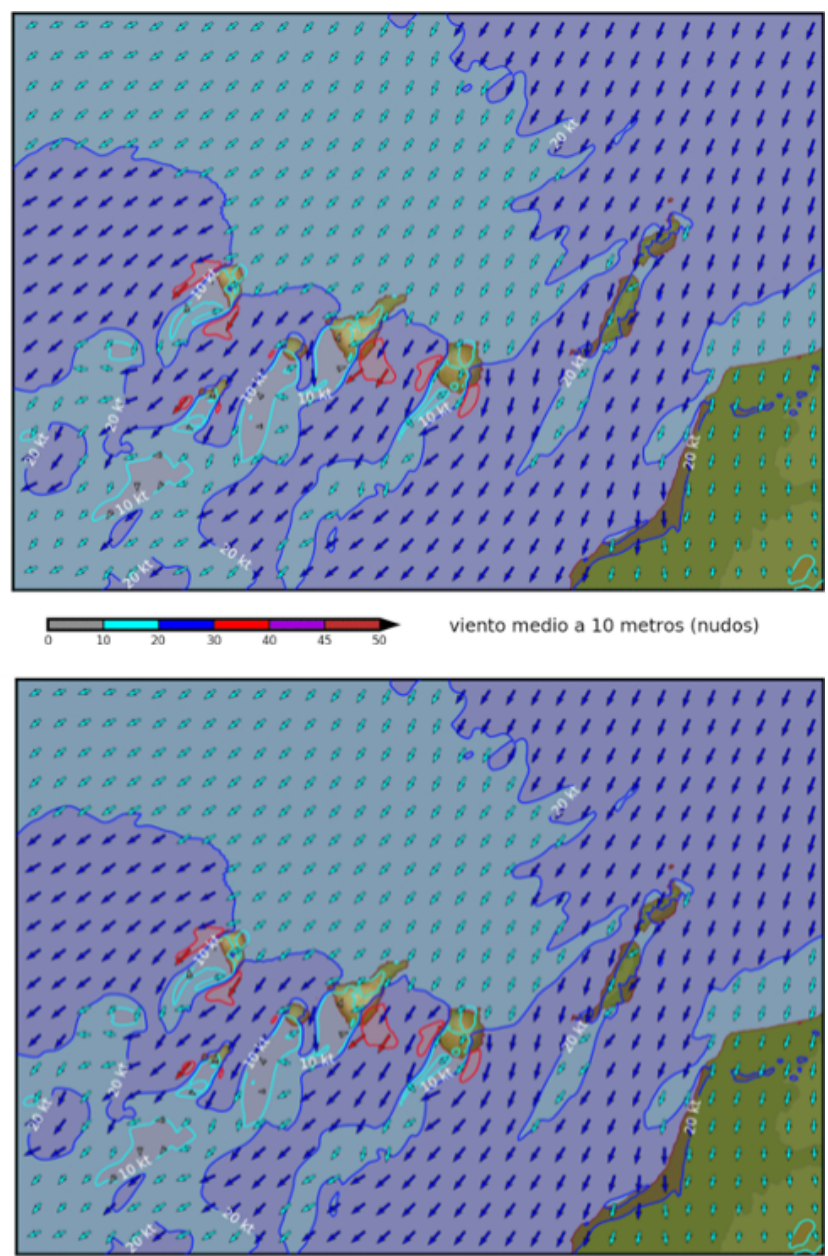

viento medio a 10 metros (nudos)

Figura 10. Campo de vientos a $10 \mathrm{~m}$ en Gran Canaria y a nivel del archipiélago el 10/05/2015 a las 14 Z, en situación de alisio moderado. Harmonie-Arome 40h1.1.

núcleos a 40 kt en color naranja). Nótese también cómo los máximos de viento quedan al sur del aeropuerto por la suma de efectos comentados anteriormente (zona de máxima aceleración y reguladores locales), en oposición al viento (20kt) y racha máxima prevista en el aeropuerto (32kt).

La imagen superior de la fig. 11 muestra la misma localización dos días más tarde, durante el sábado 12 de mayo, también a las 14Z, día en el que AEMET emitió un aviso amarillo por viento intenso en la vertiente SE de la isla. En este caso, el flujo sinóptico del alisio puede cifrarse en el rango 15-20 kt (alisio intenso), y la estructura en forma de LLCJ se muestra aún más claramente que en el caso anterior con vientos que, como mostrará el próximo subapartado, llegaron a alcanzar los 50 kt de racha máxima en la zona de Pozo Izquierdo. La imagen inferior de la misma figura muestra la situación en Tenerife Sur (también en aviso amarillo).

Como puede observarse, el aeropuerto de Tenerife Sur (GCTS) se encuentra en el seno del LLCJ y por tanto mucho más expuesto a vientos intensos en la situación habitual de alisio. El mayor problema desde el punto de vista aeronáutico no es, sin embargo, la intensidad de este viento, sino la cercanía de la línea de convergencia de vientos señalada sobre la figura debido a la presencia de la interfase LLCJ-mesobaja en las inmediaciones del aeródromo. Nótese la racha máxima prevista en el aeropuerto en la hora previa, de 47 kt, por encontrarse justo bajo el núcleo del jet.

Para mejorar la detección de los LLCJ se han tomado cortes verticales en distintos puntos, teniendo en cuenta por un lado la posición de los aeropuertos, y por otra las zonas de máxima aceleración del jet (fig. 12). El débil gradiente sinóptico bárico (descrito como $\mathbf{P}_{\mathrm{S}}$ en el epígrafe 3.1) ocasiona que el núcleo del jet esté 


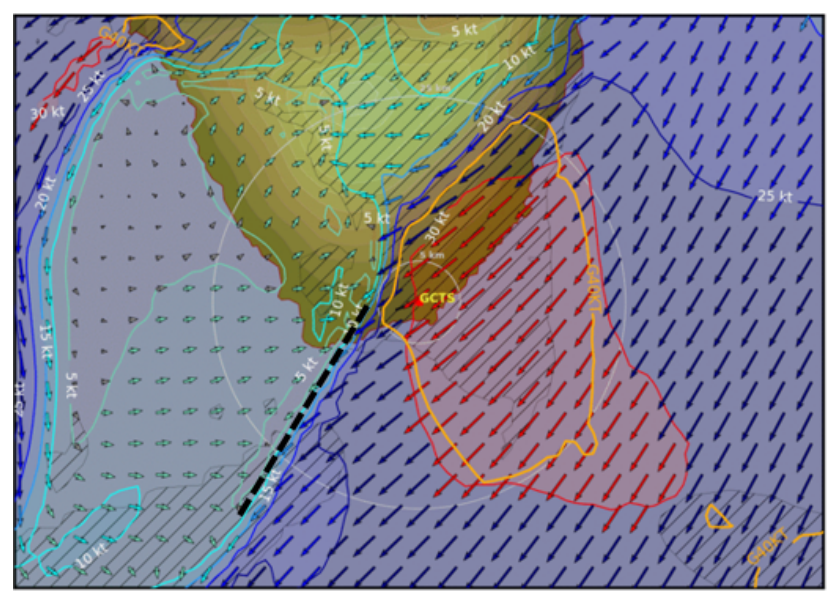

$510 \quad 1520$
5
viento medio a 10 metros (nudos)

previsto en el aeropuerto: GCTS 121400 05030kt

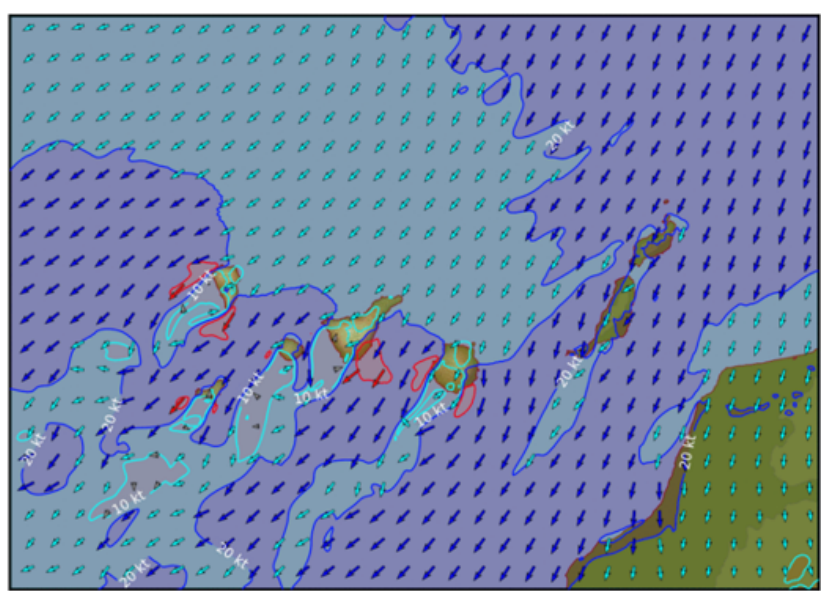

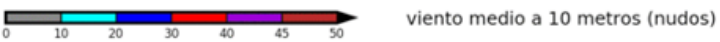

Figura 11. Campo de vientos en Gran Canaria y Tenerife el 10/05/2015 a las 14Z. Harmonie-Arome 40h1.1.

dominado por el gradiente de presión local $\left(\mathbf{P}_{\mathbf{L}}\right)$, y que su incursión sea mayor en dirección a la zona marítima (que la forma del jet sea más achatada respecto al modelo conceptual planteado en los epígrafes 2 y 3 ). Se observa también la vertiente opuesta de la isla, donde las estructuras tipo jet no se dan por la ausencia de una componente térmica (ausencia de calentamiento de la superficie).

Los tres ejemplos de la fig. 12 corresponden a jets costeros los días 6 y 15 de julio de 2018 y muestran la importancia y el efecto de la inversión térmica sobre los LLCJ y la intensidad del viento resultante en superficie. En efecto, una capa de inversión baja (por debajo de los $700 \mathrm{~m}$ ) y muy marcada (inversiones superiores a $\operatorname{los} 6^{\circ} \mathrm{C}$ ) comprime el flujo de manera muy eficiente como se ha explicado en el epígrafe anterior. El impacto de esta compresión siempre se traduce en un aumento de la velocidad más notable en superficie que en altura, donde los valores del jet siempre se mantienen elevados. Esto es lo que ocurre en las imágenes superior y central de la fig. 12, correspondientes al 6 de julio de 2019.

La imagen inferior de la fig. 12, por contra, muestra la situación del jet en Gran Canaria a la misma hora un día con inversión térmica menos marcada y a mayor altura (inferior a $6{ }^{\circ} \mathrm{C}$ ).

Estos ejemplos, además de la dependencia de la posición del núcleo del LLCJ con la altura de la capa de inversión, también ponen de manifiesto la existencia del fenómeno en la vertiente NW/W de Gran Canaria, y cómo la aceleración en el canal Anaga-Agaete no se debe a una canalización orográfica, sino a un LLCJ (el máximo no se da en el medio del canal, sino muy cerca de la costa grancanaria).
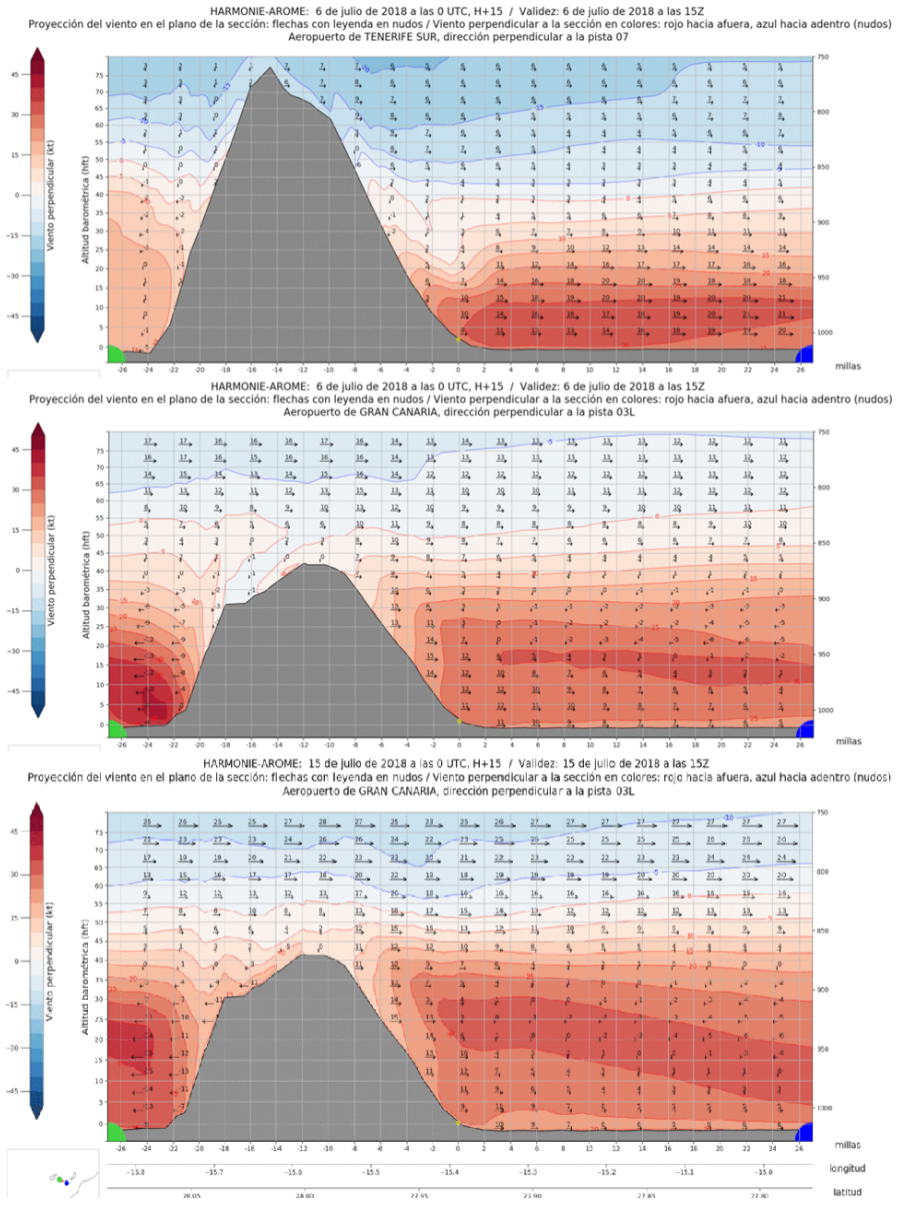

Figura 12. Cortes verticales a la altura de los aeropuertos de Tenerife (arriba) y Gran Canaria (medio) el 6 de julio de 2018 a las $15 \mathrm{Z}$ con una inversión térmica baja. La imagen inferior del 15 de julio de 2018 a las $15 \mathrm{Z}$ muestra un ejemplo con una inversión térmica elevada y poco marcada. Harmonie-Arome 40h1.1. 
Adicionalmente, en esta vertiente W/NW de Gran Canaria cabe destacar que los gradientes de presión $\mathbf{P}_{\mathrm{S}} \mathrm{y}$ $\mathbf{P}_{\mathbf{L}}$ sí están alineados, sin que ello repercuta en una potenciación adicional de los valores registrados del viento a nivel de modelos. En todo caso, la poca densidad poblacional junto con la ausencia de tráfico aéreo en la zona hace que el estudio del LLCJ en esta vertiente sea de menor interés (no así por la mar picada y su efecto sobre el tráfico marítimo).

\subsection{Reguladores locales en Gran Canaria 10-16 mayo 2018}

Volviendo a los reguladores locales del jet en superficie de Gran Canaria descritos en el epígrafe 3, se han tratado de buscar estaciones meteorológicas cercanas que permitan discernir con mayor claridad dicho efecto.

La fig. 13 muestra las rachas máximas de viento en cada uno de los días y para cada una de las estaciones (GCLP en verde, Matorral en rojo y Pozo Izquierdo en Rosa; adicionalmente, se muestra en azul el viento medio de esta última estación), donde se observa que la intensidad del viento en Pozo Izquierdo es habitualmente unos $10 \mathrm{kt}$ superior a las otras dos. ¿Por qué? Porque es la zona a sotavento del principal regulador orográfico local en la zona, la montaña de Arinaga. Se muestra también el valor aproximado de la componente sinóptica del alisio (en color negro, dato del valor del viento arrojado por el modelo H40), lo que da una buena idea del efecto potenciador del viento en los LLCJ frente a la componente sinóptica.

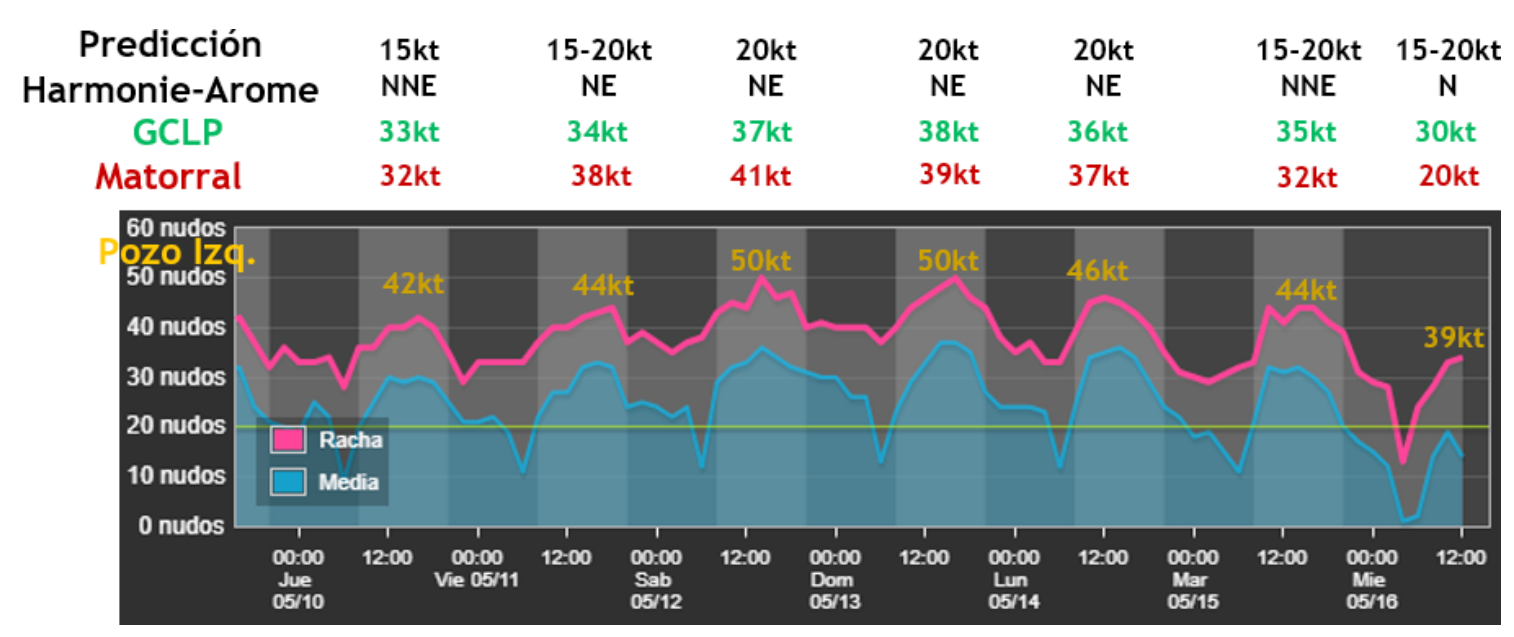

Figura 13. Fuentes: Harmonie-Arome 40h1.1., Red de observación de AEMET y estación PozoWinds.

\subsection{Cola de los jets}

Para apreciar el efecto de las colas de los jets ocasionadas por el efecto de las mesobajas a sotavento de las islas y descritos en el epígrafe 2.1, se ha utilizado el modelo WRF con tres dominios anidados con resoluciones de 9,3 y $1 \mathrm{~km}$ respectivamente, con $100 \times 100$ puntos de malla cada uno. Como condiciones iniciales se ha usado la rejilla de pronóstico global del GFS, con una resolución de $0,25^{\circ}$.

La fig. 14 muestra dos situaciones con distinta intensidad de alisio a nivel sinóptico, moderado-intenso (imagen izquierda) y débil-moderado (derecha). En este caso no se ha numerado explícitamente la intensidad del viento sino la presión para poner de manifiesto la diferencia de presión entre las vertientes a barlovento (mesoalta) y sotavento (mesobaja) del flujo en Gran Canaria. La diferencia entre estas estructuras dinámicas se hace tanto más intensa a medida que aumenta el alisio, lo que a su vez provoca que las colas de los jets persistan un mayor número de kilómetros «viento abajo» en los flancos a sotavento de las islas (cola del jet más alargada).

Como ya se ha explicado, esto supone una diferencia sustancial frente al modelo clásico de jet costero, cuyos vientos intensos suelen acabar allá donde termina la cordillera que introduce la distorsión barométrica. 

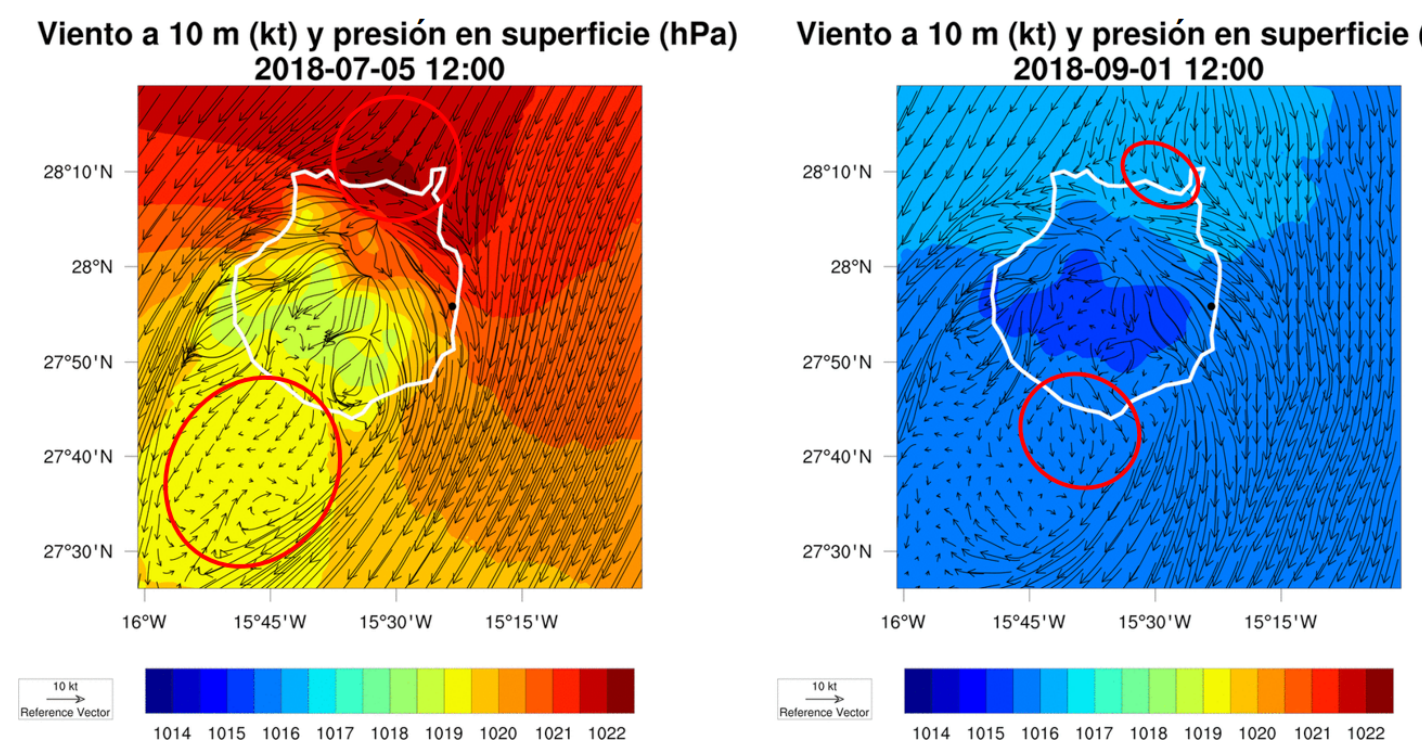

Figura 14. Vientos a $10 \mathrm{~m}$ y presiones en superficie. A la izquierda, situación de alisio moderado-intenso; a la derecha, situación de alisio débil-moderado. Fuente: WRF.

En el caso canario, la presencia de estas mesobajas a sotavento de las islas de mayor relieve resulta en que los jets persistan decenas de kilómetros sobre el océano, pudiendo superar el centenar de kilómetros en situaciones de alisio muy intenso.

\subsection{Pseudojets del S y SW}

Existe otro tipo de estructura de vientos interesante que presenta muchas similitudes con los LLCJ, pero que no cumple con todas sus condiciones tal y como se han planteado en este documento. Se han denominado como pseudojets del S y SW. Son situaciones que suelen darse puntualmente durante los meses de otoño e

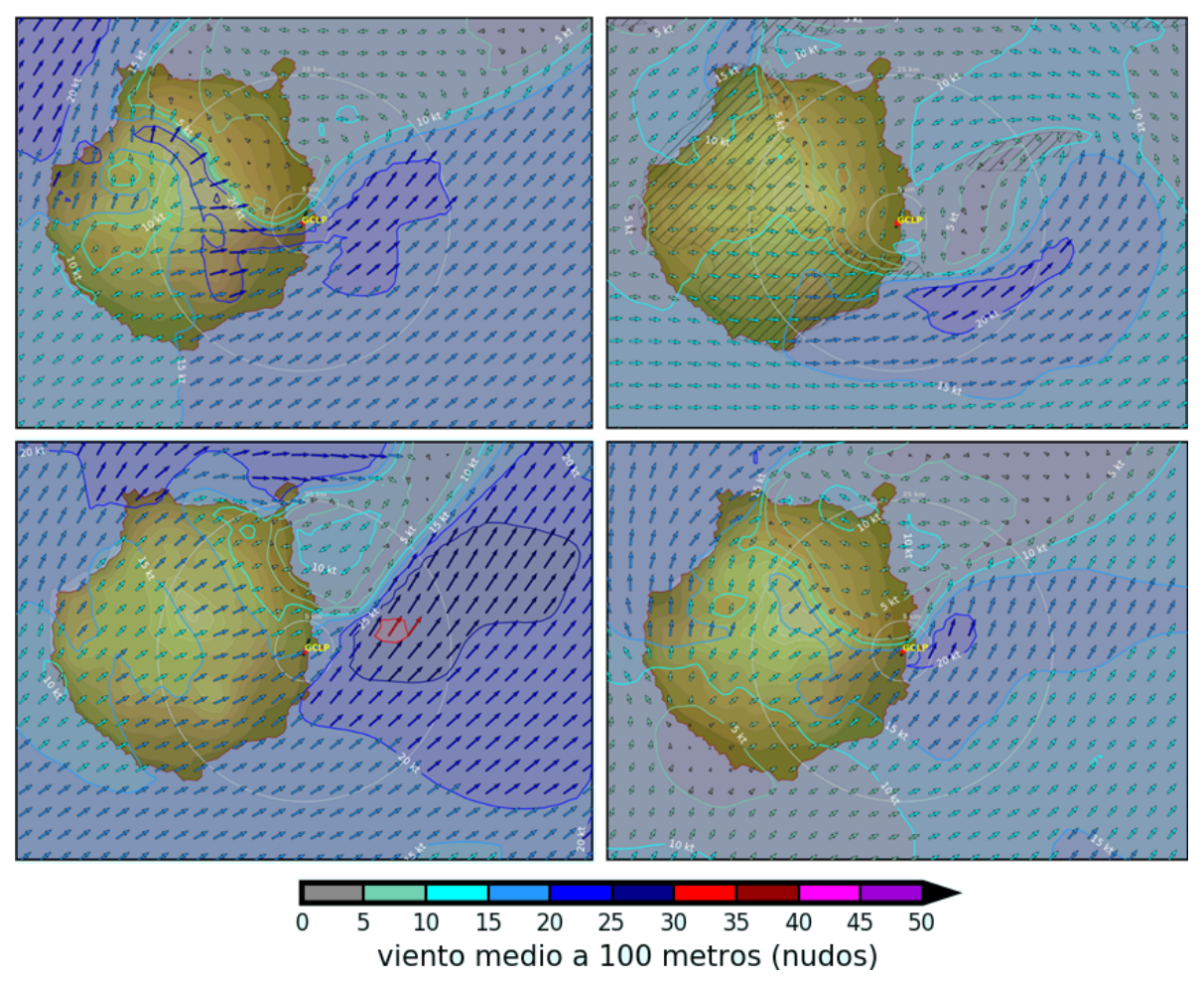

Figura 15. Pseudojets costeros del SW en Gran Canaria los días 26, 27 y 28 de febrero de 2018. Harmonie-Arome 40h1.1. 
invierno (y en menor medida también en primavera) y que suelen estar asociadas a la presencia de bajas presiones al W y NW del archipiélago, que inducen viento del S/SW sobre las islas. En tales circunstancias, aparecen unas estructuras de viento también en los flancos de las islas de mayor relieve que, al igual que los LLCJ, poseen máximos en las zonas en las que el flujo es paralelo a la costa tal y como muestran los ejemplos de la fig. 15 correspondientes al 26, 27 y 28 de febrero de 2019.

Pese a que las aceleraciones del viento se dan también en los flancos laterales de las islas (respecto a la dirección del flujo dominante), existen diferencias importantes respecto a los LLCJ expuestos en este documento:

- La capa de inversión, en caso de existir, suele encontrarse muy elevada, por encima de los 1500-2000 m. Esto choca con la situación de alta estabilidad esquematizada en la fig. 2 y propiciada por la subsidencia de un anticiclón a gran escala.

- El flujo, más que acelerarse en los flancos de las islas de mayor relieve, ya viene acelerado, al existir una borrasca al W del archipiélago.

- En consonancia con esto, el efecto de la insolación no parece ser muy relevante, ya que los máximos de viento no se dan necesariamente en horas centrales o segunda mitad del día.

- La incidencia es mucho menor (de unos pocos días al año), y solo en presencia de una baja presión semiestacionaria al W o NW del archipiélago canario (caso poco común) se hace persistente en el tiempo.

- La variabilidad intradía del viento es mucho mayor, hecho debido en buena medida a la capacidad del flujo de sobrepasar el terreno de las islas en lugar de difluir al encontrarse con ellas (por la existencia de una capa de inversión muy elevada, o incluso inexistente). Al ser el flujo sobre tierra muy sensible no solo debido a la heterogeneidad del terreno, sino también a pequeños movimiento de la baja presión, la variabilidad e intensidad de las rachas de estos pseudojets es mucho mayor.

En definitiva, frente a la situación de alta estabilidad de un LLCJ en régimen de alisio, esquematizada en la fig. 2 y propiciada por la subsidencia a nivel sinóptico de un anticiclón cercano, los pseudojets del S/SW no comparten estas características. El elevado grado de inestabilidad de la atmósfera circundante también ocasiona que dichas estructuras sean menos estables en el tiempo que sus homólogos en régimen de alisio. Este tipo de situaciones suelen ser las más desfavorables para la aeronáutica en términos de cizalladura. Dos potenciales eventos de este tipo, ocurridos en abril de 2017 y febrero de 2018 en las inmediaciones del aeropuerto de Gran Canaria, ocasionaron numerosos aterrizajes frustrados por cizalladura fuerte y han sido publicados recientemente (SUÁREZ et al., 2019).

Por último y a este respecto, las simulaciones de viento de Harmonie-Arome a 100 m como las mostradas permiten identificar con bastante precisión la posición de la base del pseudojet y dónde se encuentra la zona potencialmente de mayor cizalladura durante las maniobras de aproximación, siempre más sensible a la cizalladura que en maniobra de despegue.

\subsection{LLCJ en La Palma, El Hierro y La Gomera}

Por último, se han detectado otros LLCJ en las islas más occidentales del archipiélago, en La Palma, El Hierro y La Gomera (fig. 16). Aunque las formaciones y establecimientos de sus respectivos LLCJ cumplen las condiciones planteadas en el epígrafe 2 (MBL y upwelling; inversión térmica persistente; orografía y alta insolación; y reguladores locales en superficie), cada una posee sus particularidades y condicionantes altamente dependientes de la microescala. Su estudio pormenorizado e impacto, tal y como se ha llevado a cabo para Tenerife y Gran Canaria, rebasa los objetivos de este documento. 
En todos los casos se muestran los campos de viento medio a $10 \mathrm{~m}$ y $100 \mathrm{~m}$ sobre la superficie. El caso del LLCJ en el flanco oriental de La Gomera representa quizá el caso más complejo y particular de todos ellos por la proximidad de la isla de Tenerife, con una probable componente debida al encauzamiento orográfico del flujo entre ambas islas en situación de flujo sinóptico del N.
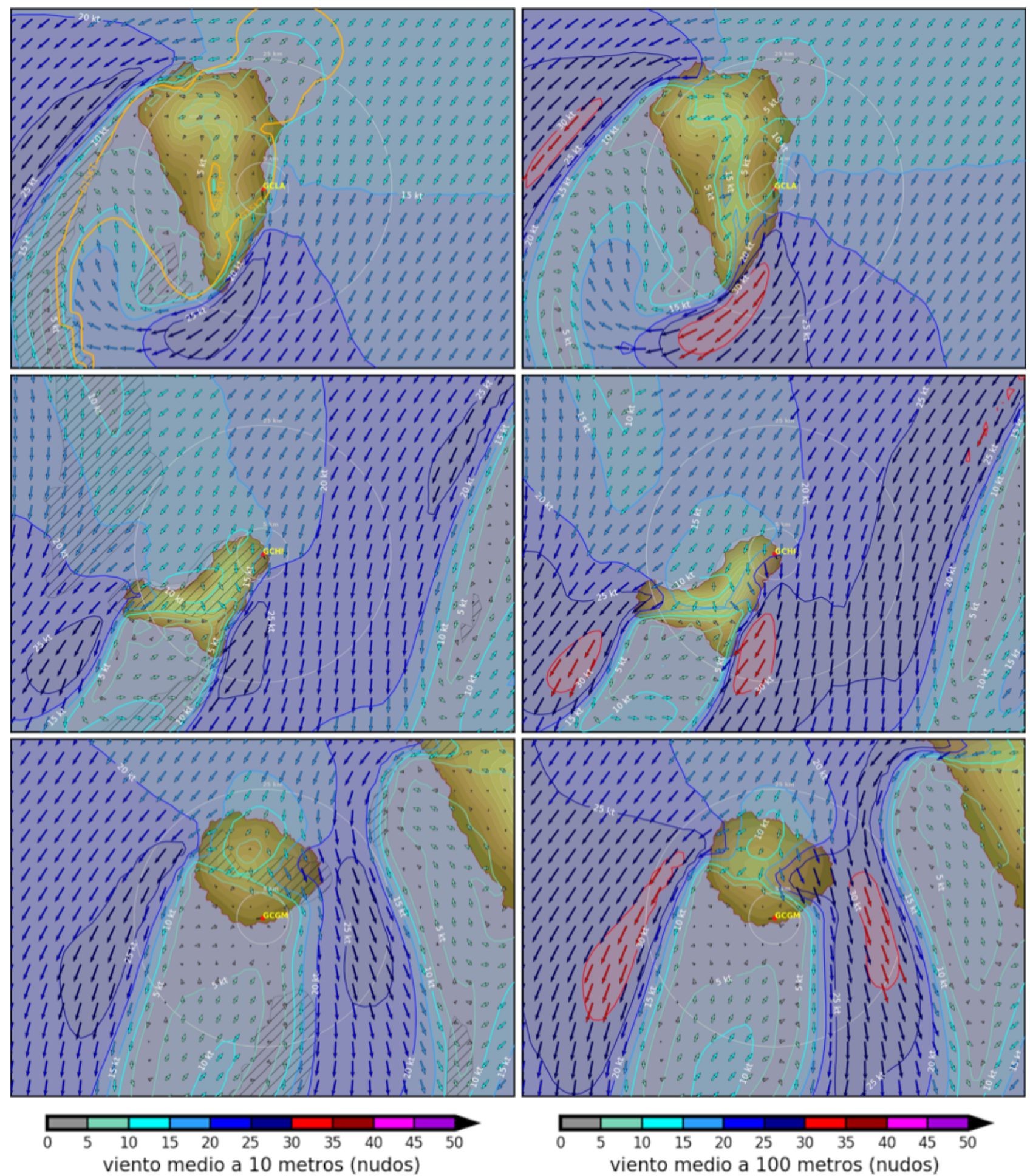

Figura 16. Campo de vientos a $10 \mathrm{~m}$ y a $100 \mathrm{~m}$ de la superficie en La Palma (arriba), El Hierro (medio) y La Gomera (abajo). Harmonie-Arome 40h1.1. 


\section{CONCLUSIONES Y FUTURAS LÍNEAS DE TRABAJO}

A pesar de su elevada ocurrencia, las estructuras en forma de jet costero en el contexto canario no habían sido identificadas como tales hasta la fecha. Ahora, y en parte gracias a la drástica mejora de la resolución de modelos en los últimos años, se han detectado y caracterizado diversos LLCJ en Tenerife y Gran Canaria, así como estructuras a priori similares en el resto de islas de mayor relieve del archipiélago (La Palma, El Hierro y La Gomera). Las simulaciones con los modelos no hidrostáticos de alta resolución Harmonie-Arome y WRF, con cortes verticales obtenidos a lo largo de las costas sureste y noroeste de Gran Canaria y Tenerife, muestran claramente la aparición de estas estructuras baroclinas en niveles bajos y su persistencia en periodos de alta estabilidad y claro dipolo barométrico (alta semipermanente de Azores y baja térmica sobre el Sáhara occidental), situación absolutamente dominante en la época estival y con una ocurrencia cercana a tres de cuatro días de media anual.

Además de su ocurrencia a pequeña escala, dos son las principales diferencias del fenómeno en Canarias frente al modelo clásico de chorro costero en costas de varios cientos de kilómetros de longitud como California o Chile.

El primero de ellos tiene que ver con la dominancia de una componente muy local de presión en dirección océano-tierra en las vertientes SE de Tenerife y SE y NW Gran Canaria, frente a un gradiente sinóptico que a estas escalas es muy débil $\left(\mathbf{P}_{\mathbf{L}}\right.$ vs. $\left.\mathbf{P}_{\mathbf{S}}\right)$. El establecimiento de este gradiente barométrico se debe a la conjunción de dos hechos: la prominencia orográfica de las islas, y su posterior reforzamiento en horas centrales y segunda mitad del día por una componente dinámica, consecuencia del calentamiento diurno del terreno. La consecuencia de esta preponderancia del gradiente local sobre el sinóptico resulta en un jet más achatado de lo normal, capaz de extenderse decenas y hasta centenares de kilómetros en dirección opuesta a la costa, y cuyo reflejo en superficie queda patente tanto en modelos como en observaciones mediante escaterometría.

El segundo es la potenciación del efecto a nivel de mesoescala-inferior (y posiblemente lindando con la microescala en el caso de islas menores como La Gomera o El Hierro) por la aparición de pares mesoalta/ mesobaja a barlovento/sotavento de las islas, especialmente de las de mayor relieve. Tal es el caso, además de en las islas de Tenerife y Gran Canaria bajo estudio en el presente paper, de La Palma, La Gomera y El Hierro; mientras que en las islas orientales del archipiélago, Lanzarote y Fuerteventura, y aunque se observan aceleraciones de viento en superficie de menor entidad, los fenómenos más representativos de viento intenso suelen obedecer más a encauzamientos orográficos que a estructuras con forma de jet (áreas de Costa Teguise y Costa Calma como mayores exponentes, respectivamente). La consecuencia de estos pares mesobaja-alta en cada una de las islas se traduce en un jet que persiste varios kilómetros en los flancos a sotavento de las respectivas islas («viento abajo»), donde la distorsión barométrica directa del relieve ya no existe, pero sí su reflejo dinámico en forma de mesobaja.

Dos son también las principales diferencias del fenómeno entre las islas de Gran Canaria y Tenerife. Mientras que en la costa SE de Tenerife tiene una forma lineal, y el viento de dirección N, NE y E es forzado orográficamente por el canal Anaga-Agaete, la forma de la isla de Gran Canaria es prácticamente circular, lo que permite que el movimiento de sendos LLCJ a lo largo de su costa según el flujo sinóptico proceda del N/NE o ENE/E. En ese sentido, se ha llevado a cabo un estudio a fondo de la disposición y los elementos orográficos locales del flujo en la costa SE de Gran Canaria por su mayor importancia a nivel aeronáutico. 


\section{REFERENCIAS}

Beardsley, R. C., Dorman, C. E., Friehe, C. A., Rosenfeld, L. K. y Winant, C. D., 1987. Local atmospheric forcing during the Coastal Ocean Dynamics Experiment: A description of the marine boundary layer atmospheric conditions over a Northern California upwelling region. Journal of Geophysical Research, 92 (C2), 1467-1488.

Bengtsson, L., Andrae, U., Aspelien, T., Batrak, Y., Calvo, J., de Rooy,W., Gleeson, E., Sass, B. H., Homleid, M., Hortal, M. et al., 2017. The Harmonie-Arome Model Configuration in the Aladin-Hirlam NWP System. Mon. Weather Rev., 145, 1919-1935.

BunKER, A. F., 1965. A low- level jet produced by air, sea, and land interactions. Report 1, Sea-Air Interaction Lab, Washington, D.C., 225-238.

Chaо, S., 1985. Coastal jets in the lower atmosphere. J. Phys. Oceanogr., 15, 361-371.

Chou, M.-D., SuÁREZ, M. J., LiAng, X.-Z. y YAN, M.-H., 2001. A thermal infrared radiation parameterization for atmospheric studies. NASA Tech. Rep. Series on Global Modeling and Data Assimilation, Vol. 19, Goddard Space Flight Center, NASA/TM-2001-104606, 56 pp.

ELLIOTT, D. L. y O'BRIEN, J. J., 1977. Observational studies of the marine boundary layer over an upwelling region. Monthly Weather Review, 105, 86-98.

Gill, A. E. y Schumann, E. H., 1979. Topographically Induced Changes in the Structure of an Inertial Coastal Jet: Application to the Agulhas Current. Journal of Physical Oceanography, 9, 975-991.

JANJIC, Z. A., 1990. The step-mountain coordinate: physics package. Mon. Weather Rev., 118, 1429-1443.

Johnson, A. y O'Brien, J. J., 1973. A study of an Oregon sea breeze event. Journal of Physical Oceanography, 5, 761-772.

Lester, P. F., 1985. Studies of the marine inversion over the San Francisco Bay area: A summary of the work of Albert Miller, 1961-1978. Bulletin of the American Meteorological Society, 66 (11), 1396-1402.

Parish, T. R., 2000. «[...] the thermal wind resulting from the strong horizontal temperature contrast between land and ocean is fundamentally responsible for the jet profile». Forcing of the summertime low-level jet along the California coast. J. Appl. Meteorol., 39, 2421-2433.

RAHN, D. A. y PARISH, T. R., 2007. Diagnosis of the forcing and structure of the coastal jet near Cape Mendocino using in situ observations and numerical simulations. J. Appl. Meteorol. Clim., 46, 1455-1468.

SAHA, S. et al., 2010. The NCEPClimate Forecast System Reanalysis. Bulletin of the American Meteorological Society, 91, 1015-1057.

Seity, Y., Brousseau, P., Malardel, S., Hello, G., Benard, P., Bouttier, F., Lac, C. y Masson, V., 2011. The AROME France convective-scale operational model. Mon. Wea. Rev., 139, 976-991.

SkAmarock, W. C. y KLEMP, J. B., 2008. A time-split nonhydrostatic atmospheric model for weather research and forecasting applications. J. Comput. Phys., 227, 3465-3485.

Suárez Molina, D., Fernández Villares, J. y Fernández González, S., 2019. Impacto de eventos de cizalladura severa en el aeropuerto de Gran Canaria. AEMET. 
Thompson, G., Field, P. R., Rasmussen, R. M. y Hall, W. D., 2008. Explicit forecasts of winter precipitation using an improved bulk microphysics scheme. Part II: Implementation of a new snow parameterization. Mon. Wea. Rev., 136, 5095-5115.

TJernström, M. y Grisogono, B., 2000. Simulations of supercritical flow around points and capes in a coastal atmosphere. J. Atmos. Sci., 57, 108-135.

ZembA, J. y FrieHE, C. A., 1987. The marine atmospheric boundary layer jet in the Coastal Ocean Dynamics Experiment. Journal of Geophysical Research, 92, 1489-1496. 